\title{
Being You by Anil Seth book review
}

\section{Patrizio Tressoldi ${ }^{1}$ \\ Science of Consciousness Research Group - Studium Patavinum \\ Università di Padova - Italy}

[version 9/10/2021]

Where do our consciousness, phenomenological experiences, feelings, desires, expectations, thoughts come from? In essence, "who are we?" according to Anil Seth (AS, 2021) one of the world's leading consciousness researcher?

AS declare his metaphysical assumption since the prologue:

"Somehow, within each of our brains, the combined activity of billions of neurons, each one a tiny biological machine, is giving rise to a conscious experience.. ”...

"For me, a science of consciousness should explain how the various properties of consciousness depend on, and relate to, the operations of the neuronal wetware inside our heads".

"We are conscious selves precisely because we are beast machines. I will make the case that experiences of being you, or of being me, emerge from the way the brain predicts and controls the internal state of the body. The essence of selfhood is neither a rational mind nor an immaterial soul. It is a deeply embodied biological process, a process that underpins the simple feeling of being alive that is the basis for all our experiences of self, indeed for any conscious experience at all. Being you is literally about your body".

"My preferred philosophical position, and the default assumption of many neuroscientists, is physicalism. This is the idea that the universe is made of physical stuff, and that conscious states are either identical to, or somehow emerge from, particular arrangements of this physical stuff. Some philosophers use the term materialism instead of physicalism, but for our purposes they can be treated synonymously"

"We are conscious beast machines, through and through".

This metaphysical or philosophical approach is still the dominant assumption of academic neuroscientists and psychologists.

How AS empirically supports such assumption? His main effort is to discuss and convince the readers that "the brain is a 'prediction machine', and that what we see, hear, and feel is nothing more than the brain's 'best guess' of the causes of its sensory inputs. Following this idea all the way through, we will see that the contents of consciousness are a kind of waking dream - a controlled hallucination - that is both more than and less than whatever the real world really is".

“perceptual experience - in this case the subjective experience of 'seeing a coffee cup' - is determined by the content of the (top-down) predictions, and not by the (bottom-up) sensory

\footnotetext{
${ }^{1}$ Email: patrizio.tressoldi@unipd.it
} 
signals. We never experience sensory signals themselves, we only ever experience interpretations of them".

In this last paragraph, AS assimilates the brain activity involved in the processing of information conveyed by the sensory organs as phenomenological subjective experiences, e.g. a coffee cup, its colors, form, uses, etc. In other words, he solves the main explanatory gap of his metaphysical assumption, known as the "hard problem", that is how the brain bioelectrical activity produces our phenomenological conscious experiences, even if it uses terms like perceptual experiences and their interpretation.

Within all the book, this "assimilation" is taken for granted and extended to the neural correlates of the experience of being me/you, free will, emotions, desires and all mental contents.

"The entirety of perceptual experience is a neuronal fantasy that remains yoked to the world through a continuous making and remaking of perceptual best guesses, of controlled hallucinations".

"Predictive processing is a theory about the mechanisms by which brains accomplish perception (and cognition, and action). The controlled hallucination view, by contrast, is about how brain mechanisms explain phenomenological properties of conscious perception".

"The experience of being me, or of being you, is a perception itself-or better, a collection of perceptions - a tightly woven bundle of neurally encoded predictions geared towards keeping your body alive. And this, I believe, is all we need to be, to be who we are".

"In the same way that 'redness' is the subjective aspect of brain-based predictions about how some surfaces reflect light, emotions and moods are the subjective aspects of predictions about the causes of interoceptive signals. They are internally driven forms of controlled hallucination".

"Thinking about the material basis of consciousness brings us back, once again, to the hard problem. The beast machine theory accelerates the dissolution of this apparent mystery"

According to AS, the heart of his "beast machine theory" theory of consciousness and self is:

"Our conscious experiences of the world around us, and of ourselves within it, happen with, through, and because of our living bodies. Our animal constitution is not merely compatible with our conscious perceptions of self and world. My proposal is that we cannot understand the nature and origin of these conscious experiences, except in light of our nature as living creatures."

"[the beast machine theory].... accelerates the dissolution of this apparent mystery [the hard problem]. By extending the controlled hallucination view to the very deepest layers of selfhood, by revealing the experience of the-self-as-really-existing as one more aspect of perceptual inference, the intuitions on which the hard problem implicitly rest are eroded even further. In particular, the hard-problem-friendly intuition that the conscious self is somehow apart from the rest of nature -a really-existing immaterial inner observer looking out onto a material external world - turns out to be just one more confusion between how things seem and how they are.

This soul is not an immaterial quiddity, nor a spiritual distillation of rationality. The beast machine view of selfhood, with its intimate ties to the body, to the persistent rhythms of the living, returns us to a place liberated from conceits of a computational mind, before Cartesian divisions of mind and 
matter, reason and non-reason. What we might call the 'soul' in this view is the perceptual expression of a deep continuity between mind and life".

Accepting this interpretation of our consciousness and ourself, is inevitable that at the end of our physical life ....

"we will have the chance to make a new peace with what happens - or does not happen - when the controlled hallucination of being you finally breaks down into nothingness. When oblivion is not an anaesthesia-induced interruption to the river of consciousness, but a return to the eternity that each of us at one time emerged from. At the end of this story, when life in the first person reaches its conclusion, perhaps it's not so bad if a little mystery remains".

Even if AS cites a return to the eternity, it is clear that in his view, there is no return at all, but only a final end of all our existence and experiences.

As with any other scientific theory or model, does AS's beast machine theory explain better than others the available empirical evidence?

Whereas both in the book and in AS's scientific papers, there is a plenty of evidence supporting the hypothesis that our brain processes most information in a predictive way in order to reduce both its energy and the uncertainty about future events, his solution of the hard problem by "the controlled hallucination view", seems more an assiom than an explanation.

If according to AS, all our mental contents and processes and consequently even his controlled hallucinations are nothing more than specific neurophysiological patterns, how is it possible they are transformed in qualitative subjective experiences, e.g. beliefs, emotions, desires, expectations, etc.?

However, in order to know these subjective phenomenological experiences for a thirdperson point of view, it is still necessary to ask people to describe them by using introspective and evaluative processes (Caraceni et al., 2002; Tressoldi, Facco, \& Lucangeli, 2017). Are these descriptions specific neurophysiological patterns (controlled hallucinations) observing themselves?

And how could we explain the way expectations, desires, suggestions, controlled emotions and intentions, cause functional and anatomical changes of brain and genes as documented by the rich literature of placebo, nocebo (Benedetti, Frisaldi, \& Shaibani, 2021), hypnosis (Casiglia et al., 2020) and meditation (Buric, Farias, Jong, Mee, \& Brazil, 2017)? How can these "controlled hallucinations" modify their biological substrate?

Moreover, how can the "controlled hallucination view" explain the reason why cultural and religious beliefs, influence behavior, habits, beliefs (e.g. Luhrmann et al., 2021)?. Similarly, how can such a "woven bundle of neurally encoded predictions geared towards keeping your body alive" explain suicide and some extreme choices like martyrdom (Sela \& Shackelford, 2014)?

Can the "beast machine theory" and the "controlled hallucinations" explain most of the socalled anomalous or non-ordinary consciousness experiences (Cardeña, Lynn, \& Krippner, 2014) like out-of-body experiences, near-death-experiences, spiritual/mystical experiences, extrasensory cognition, etc.? In the book, AS discusses only briefly the out-of-body experiences, considering them as "another species of perceptual inference" referring to the simulation of "out-of-body-like" experiences induced by perceptual tricks (Blanke \& Metzinger, 2009; Bourdin et al., 2017). However, none of these out-of-body-like experiences comprise the rich phenomenology reported by 
out-of-body experiencers (Nicholls, Pederzoli, \& Tressoldi, 2019; Tressoldi et al., 2015; Tressoldi \& Pederzoli, 2021).

Could a different metaphysical approach like idealism (Kastrup, 2018; Theise \& Kafatos, 2016), dual-aspect monism (Walach, 2020) asserting that consciousness is primary to physical and biological matter, explain both all AS's findings and the listed limitations of his theoretical/metaphysical approach? 


\section{References}

Benedetti, F., Frisaldi, E., \& Shaibani, A. (2021). Thirty Years of Neuroscientific Investigation of Placebo and Nocebo: The Interesting, the Good, and the Bad.

Https://Doi.Org/10.1146/Annurev-Pharmtox-052120-104536, 62(1). https://doi.org/10.1146/ANNUREV-PHARMTOX-052120-104536

Blanke, O., \& Metzinger, T. (2009). Full-body illusions and minimal phenomenal selfhood. Trends in Cognitive Sciences, 13(1), 7-13. https://doi.org/10.1016/j.tics.2008.10.003

Bourdin, P., Barberia, I., Oliva, R., Slater, M., Parnia, S., Waller, D., ... Alvarado, C. (2017). A Virtual Out-of-Body Experience Reduces Fear of Death. PLOS ONE, 12(1), e0169343. https://doi.org/10.1371/journal.pone.0169343

Buric, I., Farias, M., Jong, J., Mee, C., \& Brazil, I. A. (2017, June 16). What is the molecular signature of mind-body interventions? A systematic review of gene expression changes induced by meditation and related practices. Frontiers in Immunology. Frontiers Media S.A. https://doi.org/10.3389/fimmu.2017.00670

Caraceni, A., Cherny, N., Fainsinger, R., Kaasa, S., Poulain, P., Radbruch, L., ... Combes, J. . (2002). Pain measurement tools and methods in clinical research in palliative care: recommendations of an Expert Working Group of the European Association of Palliative Care. Journal of Pain and Symptom Management, 23(3), 239-255. https://doi.org/10.1016/S08853924(01)00409-2

Cardeña, E., Lynn, S. J., \& Krippner, S. (2014). Varieties of Anomalous Experience : Examining the Scientific Evidence. 2nd Edition. Washington, DC: American Psychological Association.

Casiglia, E., Finatti, F., Tikhonoff, V., Stabile, M. R., Mitolo, M., Albertini, F., ... Venneri, A. (2020). Mechanisms of hypnotic analgesia explained by functional magnetic resonance (fMRI). The International Journal of Clinical and Experimental Hypnosis, 68(1), 1-15. https://doi.org/10.1080/00207144.2020.1685331

Kastrup, B. (2018). The Universe in Consciousness. Journal of Consciousness Studies, 25(5-6), $125-155$.

Luhrmann, T. M., Weisman, K., Aulino, F., Brahinsky, J. D., Dulin, J. C., Dzokoto, V. A., ... Smith, R. E. (2021). Sensing the presence of gods and spirits across cultures and faiths. Proceedings of the National Academy of Sciences, 118(5), e2016649118. https://doi.org/10.1073/pnas.2016649118

Nicholls, G., Pederzoli, L., \& Tressoldi, P. (2019). The phenomenology of spontaneous and hypnotically induced Out-of-Body Experiences: A comparison. MindArxiv. https://doi.org/10.31231/OSF.IO/PQCER

Sela, Y., \& Shackelford, T. K. (2014). The myth of the myth of martyrdom. Behavioral and Brain Sciences, 37(4), 376-377. https://doi.org/10.1017/S0140525X13003488

Seth, A. (2021). Being You. A new Science of Consciousness. Faber \& Faber Ltd, London UK

Theise, N. D., \& Kafatos, M. C. (2016). Fundamental awareness: A framework for integrating science, philosophy and metaphysics. Communicative \& Integrative Biology, 9(3), e1155010. https://doi.org/10.1080/19420889.2016.1155010

Tressoldi, P. E., Pederzoli, L., Caini, P., Ferrini, A., Melloni, S., Prati, E., ... Trabucco, A. (2015). Hypnotically Induced Out-of-Body Experience: How Many Bodies Are There? Unexpected Discoveries About the Subtle Body and Psychic Body. SAGE Open, 5(4). 
https://doi.org/10.1177/2158244015615919

Tressoldi, P., Facco, E., \& Lucangeli, D. (2017). On the primacy and irreducible nature of firstperson versus third-person information. F1000Research, 6(99).

https://doi.org/10.12688/f1000research.10752.1

Tressoldi, P., \& Pederzoli, L. (2021). What is it like to be in Out-of-Body? Phenomenal accounts of experiencers. MindArxiv. https://doi.org/10.31231/OSF.IO/5VWMG

Walach, H. (2020). Inner Experience - Direct Access to Reality: A Complementarist Ontology and Dual Aspect Monism Support a Broader Epistemology. Frontiers in Psychology, 11, 640. https://doi.org/10.3389/fpsyg.2020.00640 